\title{
Three dimensional evaluation of alveolar bone changes in response to different rapid palatal expansion activation rates
}

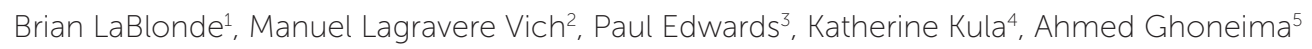

DOI: $h$ ttp://dx.doi.org/10.1590/2177-6709.22.1.089-097.oar

\begin{abstract}
Introduction: The aim of this multi-center retrospective study was to quantify the changes in alveolar bone height and thickness after using two different rapid palatal expansion (RPE) activation protocols, and to determine whether a more rapid rate of expansion is likely to cause more adverse effects, such as alveolar tipping, dental tipping, fenestration and dehiscence of anchorage teeth. Methods: The sample consisted of pre- and post-expansion records from 40 subjects (age 8-15 years) who underwent RPE using a 4-banded Hyrax appliance as part of their orthodontic treatment to correct posterior buccal crossbites. Subjects were divided into two groups according to their RPE activation rates $(0.5$ $\mathrm{mm} /$ day and $0.8 \mathrm{~mm} /$ day; $\mathrm{n}=20$ each group). Three-dimensional images for all included subjects were evaluated using Dolphin Imaging Software 11.7 Premium. Maxillary base width, buccal and palatal cortical bone thickness, alveolar bone height, and root angulation and length were measured. Significance of the changes in the measurements was evaluated using Wilcoxon signed-rank test and comparisons between groups were done using ANOVA. Significance was defined at $p \leq 0.05$. Results: RPE activation rates of $0.5 \mathrm{~mm}$ per day (Group 1 ) and $0.8 \mathrm{~mm}$ per day (Group 2) caused significant increase in arch width following treatment; however, Group 2 showed greater increases compared to Group 1 $(p<0.01)$. Buccal alveolar height and width decreased significantly in both groups. Both treatment protocols resulted in significant increases in buccal-lingual angulation of teeth; however, Group 2 showed greater increases compared to Group $1(p<0.01)$. Conclusion: Both activation rates are associated with significant increase in intra-arch widths. However, $0.8 \mathrm{~mm} /$ day resulted in greater increases. The $0.8 \mathrm{~mm} /$ day activation rate also resulted in more increased dental tipping and decreased buccal alveolar bone thickness over $0.5 \mathrm{~mm} /$ day.
\end{abstract}

Keywords: Rapid palatal expansion. Activation rates. Cone beam computed tomography.

Introdução: o objetivo do presente estudo retrospectivo multicêntrico foi quantificar as alterações na altura e na espessura do osso alveolar após o uso de dois diferentes protocolos de ativação na expansão rápida da maxila (ERM), bem como determinar se uma taxa de expansão mais rápida tem maior probabilidade de causar mais efeitos adversos, tais como inclinação dos dentes e do processo alveolar, fenestração e deiscência dos dentes de ancoragem. Métodos: a amostra consistiu de registros pré- e pós-expansão de 40 indivíduos (com idades entre 8 e 15 anos) que se submeteram à expansão rápida da maxila usando o aparelho Hyrax com quatro bandas como parte de seu tratamento ortodôntico para correção da mordida cruzada posterior. Os indivíduos foram divididos em dois grupos, de acordo com a taxa de ativação na expansão rápida da maxila $(0,5 \mathrm{~mm} /$ dia e $0,8 \mathrm{~mm} /$ dia; $\mathrm{n}=20$ cada grupo). Imagens tridimensionais de todos os indivíduos da amostra foram avaliadas com o uso do software Dolphin Imaging v.11.7 Premium. Foram analisadas as seguintes medidas: largura da base da maxila, espessura das corticais ósseas vestibular e lingual, altura do osso alveolar, angulação e comprimento das raízes. A significância das alterações nessas medidas foi avaliada com o teste não paramétrico de Wilcoxon e as comparações entre os grupos foram feitas usando a ANOVA. A significância foi definida como $p \leq 0,05$. Resultados: as taxas de ativação na ERM de 0,5mm/dia (Grupo 1) e 0,8mm/dia (Grupo 2) causaram aumento significativo na largura da arcada após o tratamento. Porém, o Grupo 2 apresentou maior aumento, se comparado ao Grupo 1 ( $p<0,01)$. A altura e a largura do osso alveolar vestibular diminuíram significativamente em ambos os grupos. Ambos os protocolos de tratamento resultaram em aumento significativo na inclinação vestibulolingual dos dentes. Porém, o Grupo 2 apresentou maior aumento, em comparação ao Grupo 1 ( $p<0,01)$. Conclusão: ambas as taxas de ativação estão associadas a um aumento significativo nas larguras intra-arcada; entretanto, a taxa de $0,8 \mathrm{~mm} /$ dia resultou em maior aumento. Essa mesma taxa de ativação também resultou em maior inclinação dos dentes e em redução mais acentuada da espessura do osso alveolar vestibular.

Palavras-chave: Expansão rápida da maxila. Taxas de ativação. Tomografia computadorizada de feixe cônico.

\footnotetext{
Orthodontic Resident, Department of Orthodontics and Oral Facial Genetics, Indiana University School Dentistry, Indianapolis, IN, USA.

${ }^{2}$ Clinical Assistant Professor, Department of Dentistry, Orthodontic Graduate Program, University of Alberta, Edmonton, Canada.

${ }^{3}$ Professor, Department of Oral Pathology, Medicine and Radiology, Indiana University School of Dentistry, Indianapolis, IN, USA.

${ }^{4}$ Chair and Jarabak Endowed Professor, Department of Orthodontics and Oral Facial Genetics, Indiana University School Dentistry, Indianapolis, IN, USA. ${ }^{5}$ Assistant professor, Department of Orthodontics and Oral Facial Genetics, Indiana University School of Dentistry, Indianapolis, IN, USA. Lecturer, Department of Orthodontics, Faculty of Dental Medicine, Al-Azhar University, Cairo, Egypt.
}

How to cite this article: LaBlonde B, Vich ML, Edwards P, Kula K, Ghoneima A. Three dimensional evaluation of alveolar bone changes in response to different rapid palatal expansion activation rates. Dental Press J Orthod. 2017 JanFeb;22(1):89-97. DOI: http://dx.doi.org/10.1590/2177-6709.22.1.089-097.oar

Submitted: June 27, 2016 - Revised and accepted: October 05, 2016

" The authors report no commercial, proprietary or financial interest in the products or companies described in this article.

» Patients displayed in this article previously approved the use of their facial and intraoral photographs, radiographs or CBCT images.

Contact address: Ahmed Ghoneima

E-mail: aghoneim@iu.edu 


\section{INTRODUCTION}

Rapid palatal expansion (RPE) is a therapeutic orthodontic treatment used to address deficiencies of the maxilla in the transverse dimension such as bilateral crossbite and constricted maxilla, as well as to increase dental arch perimeter in patients with tooth-size and arch-length discrepancies., ${ }^{1,2}$ Palatal expanders are frequently 2- or 4-banded trans-palatal appliances that expand the maxillary arch via a jackscrew mechanism that the patient turns according to the orthodontist's activation protocol. Heavy, intermittent forces are transmitted through the anchorage teeth to cause opening of the midpalatal suture, and thus, expansion of the maxilla., RPE also opens the circumzygomatic and circummaxillary sutural systems, specifically the nasal, maxillaryzygomatic sutures, and zygomatic-temporal sutures.,

RPE causes movement of the maxilla downward and forward during suture opening. ${ }^{7.8}$ The maxilla and palatine bones move apart during RPE, along with the pterygoid processes of the sphenoid bone. ${ }^{9}$ Christie et $\mathrm{a}^{10}$ demonstrated that the nasal cavity increased by one-third the width of the opening of the jackscrew appliance. The midpalatal suture opens in an unparallel manner anteroposteriorly and triangularly infero-superiorly, with the apex in the nasal cavity and the base of the triangle at the palate. ${ }^{10}$ The widest portion of skeletal expansion is seen at the anterior nasal spine and diminishes posteriorly towards the posterior nasal spine., ${ }^{9,11,12}$

Despite these intended skeletal changes, RPE may cause unfavorable changes to the dentition and alveolar bone, such as buccal tipping of the anchorage teeth, dehiscence, fenestration and root resorption. ${ }^{3,6}$ Ghoneima et $\mathrm{al}^{13}$ reported that maxillary alveolar width increases more than maxillary base width, supporting the idea that bone tipping might explain the majority of expansion. ${ }^{13} \mathrm{Krebs}^{14}$ indicated that, in adolescents, $65 \%$ of the total expansion was shown to be the result of dental movement or tipping.

The palatal expander generates heavy, intermittent forces as much as $10 \mathrm{~kg}$, which initially lead to compression of the periodontal ligament, causing bending of alveolar bone and tipping of anchorage teeth. ${ }^{3,15,16}$ The angulation between molars increases from $1^{\circ}$ to $24^{\circ}$ during expansions and these changes are due to alveolar bending and tipping of the anchorage teeth. ${ }^{17} \mathrm{Buccal}$ alveolar crest levels decrease in all maxillary posterior teeth immediately after RPE, which may be attributed to the tipping of posterior teeth. This tipping may cause resorption of alveolar crestal bone. In addition, residual loads may cause roots to move buccally towards anchorage teeth, decreasing buccal cortical bone. ${ }^{18}$ Rungcharessaeng et $\mathrm{a}^{19}$ verified that buccal bone thickness decreases after RPE and that marginal bone loss was considerably apparent three months after expansion. ${ }^{19}$ RPE also causes root resorption. Langford and $\operatorname{Sims}^{20}$ indicated that root resorption occurs mainly on the buccal surface of teeth. However, minor resorption also occurs on the apical and coronal parts..$^{21,22}$

The aim of the current multi-center retrospective study was to measure and quantify changes in alveolar bone height and thickness after two different activation protocols of RPE, using three-dimensional cone beam computed tomography (3D CBCT). The second aim was to evaluate the adverse effects associated with both activation protocols and to determine whether a more rapid rate of expansion is likely to cause more alveolar tipping, dental tipping, fenestration and dehiscence of anchorage teeth.

\section{MATERIAL AND METHODS}

The sample consisted of orthodontic records of forty patients who underwent RPE using Hyrax appliance as a part of their orthodontic treatment to correct bilateral buccal crossbite. Patients' age ranged from 8 to 15 years. All forty patients were divided into two groups according to the activation rates. Group 1 consisted of twenty patients from Alberta, Canada who performed two turns per day $(0.25 \mathrm{~mm} /$ turn $)$ with a total of $0.5 \mathrm{~mm} /$ day and had a CBCT image taken pre-expansion $\left(T_{1}\right)$ and 3 months post-expansion $\left(\mathrm{T}_{2}\right)$. The 4-banded Hyrax appliance (Dentaurum, Ispringen, Germany) was attached to permanent first molars and first premolars. If premolars were not present (in two cases from Group 2), the bands were cemented to the deciduous first molars. The size of the wire was 0.036 " stainless steel wire. The wires were soldered from the palatal side only and no buccal wires were used in both groups. The CBCT images were acquired with the iCat system (Imaging Sciences International, Hatfield, PA) at $0.3 \mathrm{~mm}$ voxel, $8.9 \mathrm{sec}$, large field of view, at $120 \mathrm{kV}$ and $20 \mathrm{~mA}$. Group 2 consisted of twenty patients from Cairo, Egypt who performed four turns per day $(0.2 \mathrm{~mm} /$ turn $)$ with a total of $0.8 \mathrm{~mm} /$ day and had a CT scan taken pre-expansion $\left(\mathrm{T}_{1}\right)$ and 3 months post-expansion $\left(\mathrm{T}_{2}\right)$. The $\mathrm{CT}$ scans were 
taken with the multiplanar spiral CT machine (X vision EX, General Electric 'GE' Corporation Medical Systems Company, New York) at $0.4 \mathrm{~mm}$ voxel, $25 \mathrm{~cm}$ FOV, $120 \mathrm{kV}$, and $20 \mathrm{~mA}$, with scanning time of $2 \mathrm{~s} /$ section. Expansion in both groups was completed once the maxillary palatal cusps occluded with the mandibular buccal cusps. The average activation time was two weeks. The appliance was left in situ as a passive retainer for three months and then was removed. The digital images were measured using the Dolphin Imaging software v.11.7 Premium (Dolphin Imaging, Chatsworth, CA). The study was approved by the Institutional Review Board (IRB \#1406256293) of Indiana University-Purdue University Indianapolis (IUPUI) and written informed consent was obtained from all subjects.

Each image was oriented from the sagittal view with the coronal plane passing through the long axis of each tooth, and from the coronal view with the axial plane passing through the lower border of orbital rims and the mid-sagittal plane aligned with the skeletal midline (Fig 1). Coronal slices were used to measure the amount of skeletal and dental expansion, angulation of teeth, buccal bone width and alveolar height. Each CBCT measurement for each tooth was made on standardized slices created parallel to the long axis of the tooth (Fig 1). Measurements were performed using measurement tool in Dolphin Imaging (Figs 2-4 and Table 1). Measurements for the maxillary first molars, first premolars and canines were recorded at the level of CEJ, mid-root and apexes. Maxillary base width and maxillary alveolar width were measured on the coronal sections. Measurements of inter-molar, inter-premolar and inter-canine widths were measured on the axial plane. Incidence of fenestrations and dehiscence was verified by means of radiographic examination.

\section{Statistical analysis}

All parameters were measured twice by the same examiner one week apart, to assess intrarater repeatability, which was evaluated using summary statistics for the differences between the repeated measurements, intraclass correlation coefficients (ICCs), and Bland-Altman plots. The two groups were compared for differences in pre-treatment measurements using one-way ANOVA. The groups were then compared for differences in the post-treatment measurements and measurement changes, using analysis of covariance on the ranks of the data, with the pre-treatment measurements used as the covariants. Significance of the changes in the measurements from pre- to post-treatment was evaluated using a Wilcoxon Signed-Rank test separately for each group adopting $p \leq 0.05$ as significant.

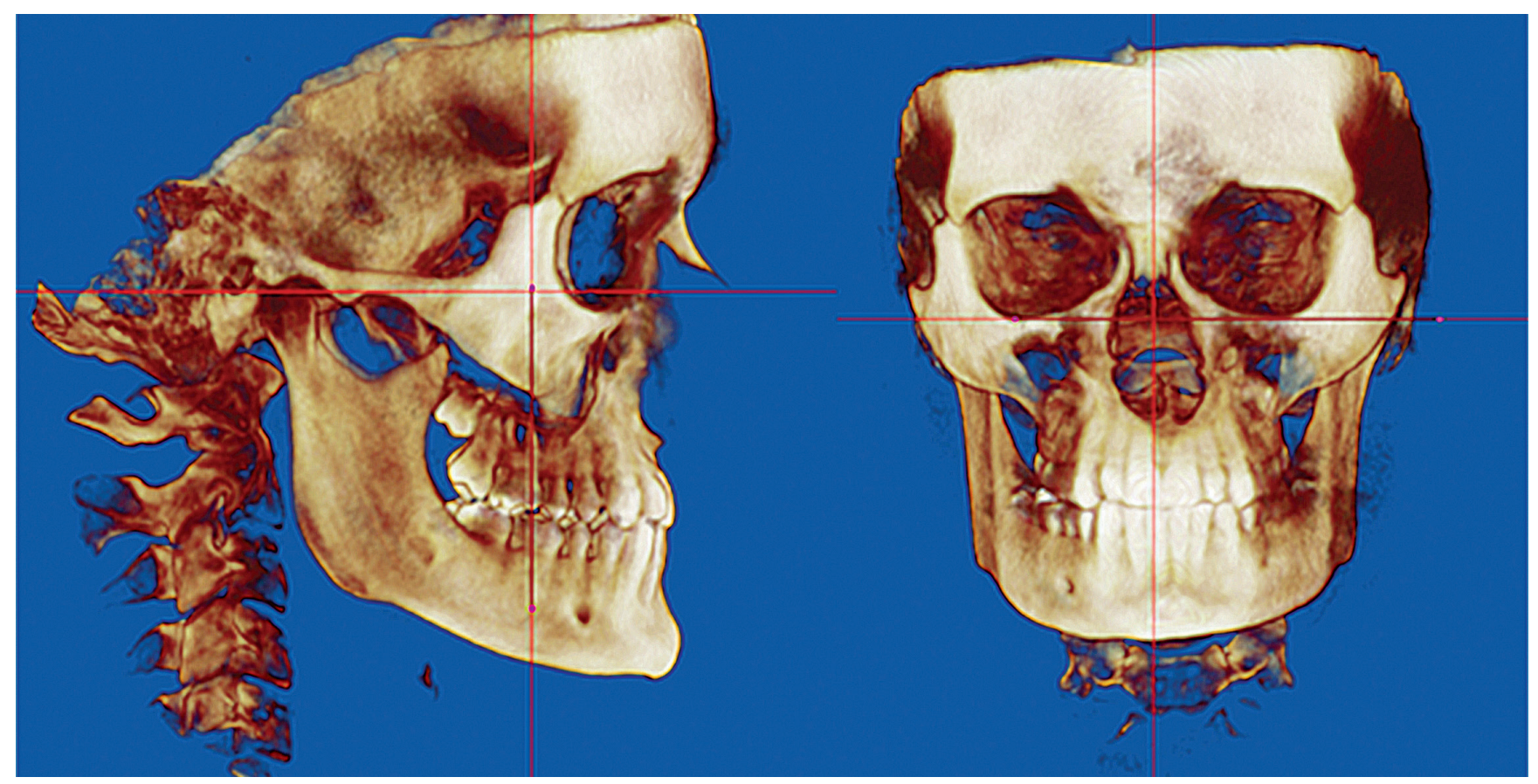

Figure 1 - Orientation in sagittal plane and in coronal plane. 


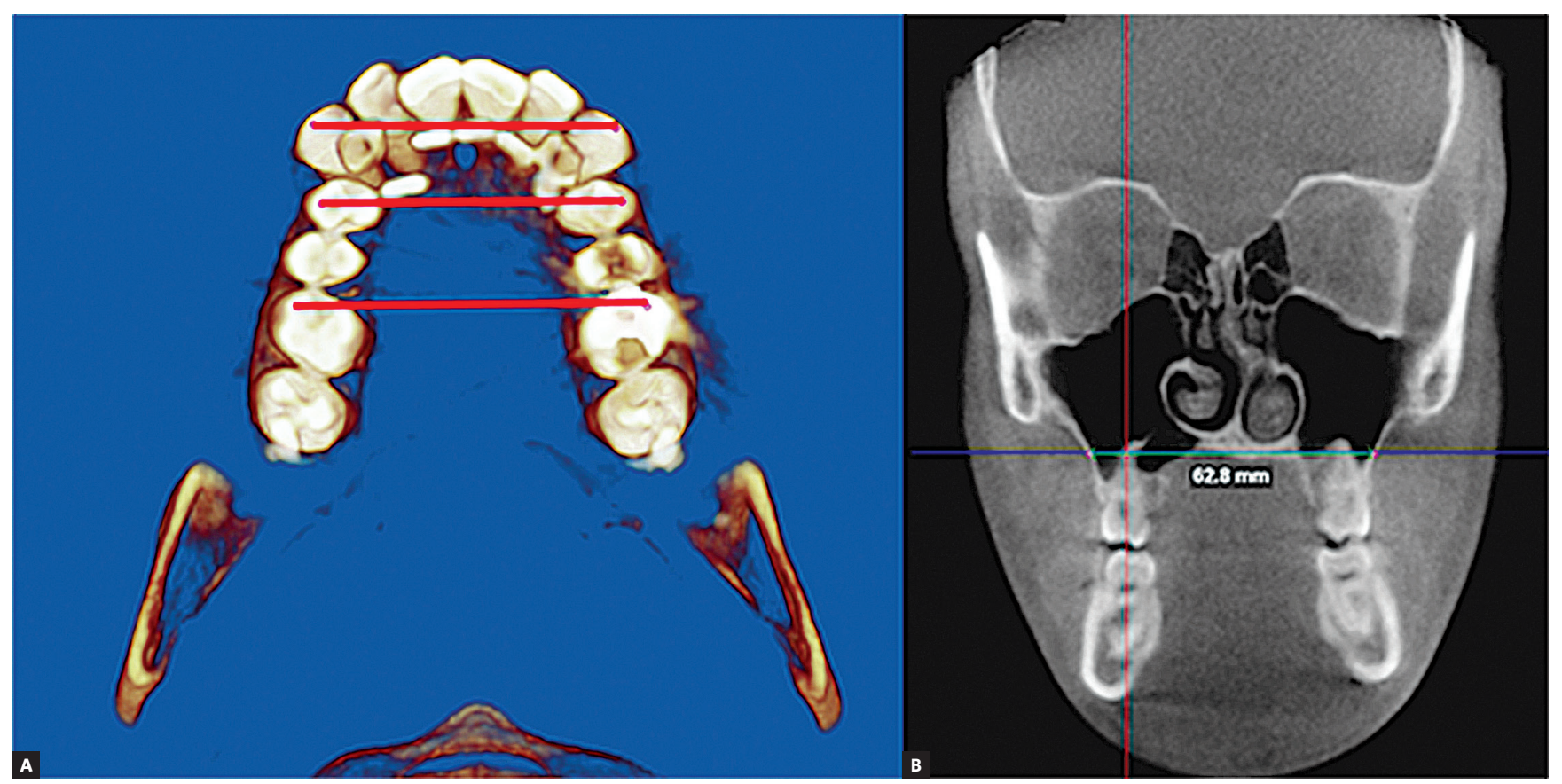

Figure 2 - Intra-arch widths (A) and maxillary base width (B)

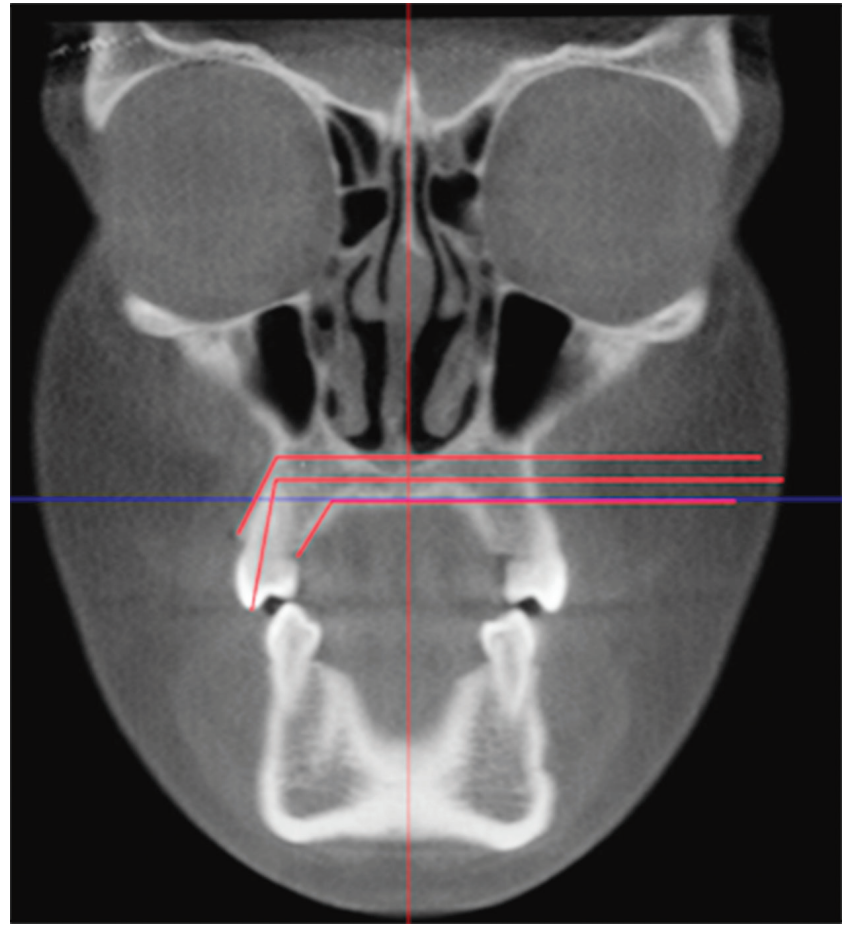

Figure 3 - Buccolingual angulation, and buccal and palatal alveolar tipping.

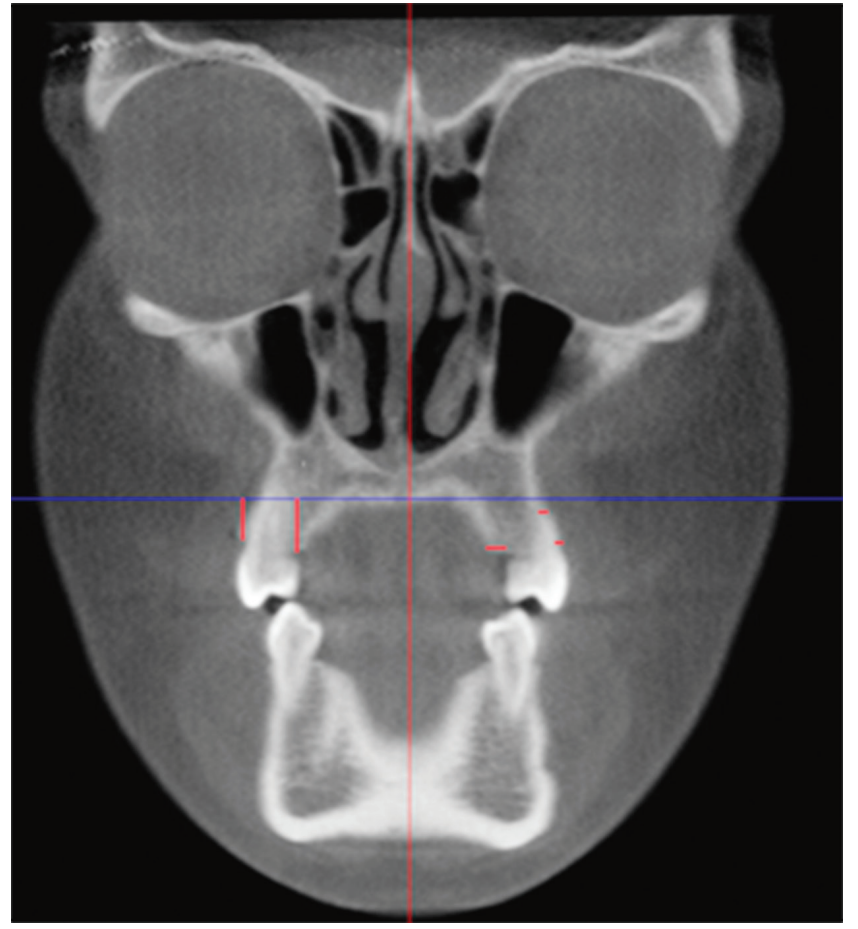

Figure 4 - Buccal and palatal alveolar height and width. 
Table 1 - Definition of parameters used in the study.

\begin{tabular}{|c|c|}
\hline Parameters & Definitions \\
\hline Inter-canine width (mm) (Fig 2) & Linear distance between the cusp tip of the right maxillary canine to cusp tip of the left maxillary canine \\
\hline Inter-premolar width (mm) (Fig 2) & $\begin{array}{l}\text { Linear distance between the buccal cusp tip of the right maxillary premolar to buccal cusp tip of the left } \\
\text { maxillary premolar }\end{array}$ \\
\hline Inter-molar width (mm) (Fig 2) & $\begin{array}{l}\text { Linear distance between the mesiobuccal cusp tip of the right maxillary first molar to mesiobuccal cusp tip of } \\
\text { the left maxillary first molar }\end{array}$ \\
\hline Maxillary base width (mm) (Fig 2) & $\begin{array}{l}\text { Linear distance between cortical plates of maxillary bone through the most inferior aspect of roof of maxillary } \\
\text { bone, measured parallel to a line perpendicular to midsagittal plane }\end{array}$ \\
\hline $\begin{array}{l}\text { Buccolingual angulation (degrees) of right and left } \\
\text { first permanent molar (Fig 3) }\end{array}$ & $\begin{array}{l}\text { Buccolingual inclination of tooth measured as the angle between a line tangent to the base of nose } \\
\text { (representing the lower limits of the nasal cavity on the right and left sides) and a line passing through the } \\
\text { buccal cusp and apex of palatal root of maxillary first permanent molars }\end{array}$ \\
\hline $\begin{array}{l}\text { Buccolingual angulation (degrees) of right and left } \\
\text { first premolars (Fig 3) }\end{array}$ & $\begin{array}{l}\text { Buccolingual inclination of tooth measured as the angle between a line tangent to the base of nose and } \\
\text { other line passing through the buccal cusp and apex of palatal root of maxillary first premolars }\end{array}$ \\
\hline $\begin{array}{l}\text { Buccolingual angulation (degrees) of permanent } \\
\text { canines (Fig 3) }\end{array}$ & $\begin{array}{l}\text { Buccolingual inclination of tooth measured as the angle between a line tangent to the base of nose and } \\
\text { other line passing through the cusp and apex of canines }\end{array}$ \\
\hline Alveolar Tipping (Buccal) (Fig 3) & $\begin{array}{l}\text { Angular measurement from a line parallel to the long axis of buccal alveolar bone and a line parallel to } \\
\text { maxillary sinus floor }\end{array}$ \\
\hline Alveolar Tipping (Palatal) (Fig 3) & $\begin{array}{l}\text { Angular measurement from a line parallel to the long axis of palatal alveolar bone and a line parallel to } \\
\text { maxillary sinus floor }\end{array}$ \\
\hline Buccal alveolar width (mm) (Fig 4) & Linear distance from root to the outermost point of buccal plate, measured for both right and left sides \\
\hline Palatal alveolar width (mm) (Fig 4) & Linear distance from root to the outermost point of palatal plate, measured for both right and left sides \\
\hline Buccal and palatal alveolar height (mm) (Fig 4) & Linear distance from the tip of the alveolar bone to a horizontal line tangent to the floor of the maxillary sinus \\
\hline
\end{tabular}

\section{RESULTS}

Values for means, standard deviations and minimum and maximum measurements and changes between time points were recorded for pre-treatment and posttreatment measurements for all groups (Tables 2 and 3). The results demonstrated that both activation rates increased intra-arch widths with the greatest amount of increase occurring more posteriorly and less expansion occurring across the canines; however, activating $0.8 \mathrm{~mm} /$ day resulted in greater increases compared to activating $0.5 \mathrm{~mm} /$ day. Activating $0.5 \mathrm{~mm} /$ day increased the maxillary base width across the canines and premolars, whereas activating $0.8 \mathrm{~mm} /$ day increased the maxillary base width across canines, premolars and molars. When activating $0.8 \mathrm{~mm} /$ day, the increase in maxillary base width was greater at the premolars and canines more than the increase in maxillary base width when activating $0.5 \mathrm{~mm} /$ day.

Both activation rates demonstrated significant increase in the buccal crown tipping of molars and premolars; however, the change in buccolingual angulation was greater when activating $0.8 \mathrm{~mm} /$ day compared to activating $0.5 \mathrm{~mm} /$ day. Both activation rates increased buccal tipping of the buccal alveolar bone which supports the maxillary first molars, and the increase was greater when activating $0.8 \mathrm{~mm} /$ day compared to activating $0.5 \mathrm{~mm} /$ day.

Both activation rates caused significant changes in the height of buccal alveolar bone supporting the teeth. Activating $0.8 \mathrm{~mm} /$ day caused significant decreases in the height of buccal alveolar bone at the canines, premolars and molars; whereas activating $0.5 \mathrm{~mm} /$ day caused significant decreases at the maxillary first premolars and right maxillary first molar. Both activation rates caused significant changes in the width of buccal alveolar bone supporting the teeth. Activating $0.5 \mathrm{~mm} /$ day caused significant decreases in the width of buccal alveolar bone at the canines, first premolars, and first molars; whereas activating $0.8 \mathrm{~mm} /$ day caused significant decreases in the width of buccal alveolar bone at the right maxillary canine, right maxillary first premolars and right maxillary first molars. Dehiscences were reported in two cases in each group. Dehiscences incidences were observed in the post-expansion images of both maxillary first premolars and maxillary first molars. 
Table 2 - Descriptive statistics of Group 1 (0.5 mm/day): measures changes from pre- to post-expansion.

\begin{tabular}{|c|c|c|c|c|c|c|c|c|c|c|c|}
\hline \multirow{2}{*}{\multicolumn{2}{|c|}{ Group 1 (0.5 mm per day) }} & \multicolumn{3}{|c|}{ Pre-expansion } & \multicolumn{3}{|c|}{ Post-expansion } & \multicolumn{3}{|c|}{ Change } & \multirow{2}{*}{ (p-Value) } \\
\hline & & Mean (SD) & Min & $\operatorname{Max}$ & Mean (SD) & Min & $\operatorname{Max}$ & Mean (SD) & Min & Max & \\
\hline \multirow{3}{*}{ Intra-arch width } & Canine & $33.1(7.6)$ & 3.4 & 40.4 & $36.4(3.0)$ & 30.0 & 41.5 & $3.3(6.9)$ & 0.0 & 31.6 & $<0.0001$ \\
\hline & Premolar & $39.5(3.5)$ & 33.5 & 46.8 & $44.1(3.3)$ & 39.0 & 50.7 & $4.6(2.2)$ & 0.2 & 8.1 & $<0.0001$ \\
\hline & Molar & $47.5(3.4)$ & 40.2 & 54.3 & $52.3(3.3)$ & 44.4 & 58.9 & $4.8(2.5)$ & -0.5 & 8.5 & $<0.0001$ \\
\hline \multirow{3}{*}{$\begin{array}{l}\text { Maxillary base } \\
\text { width }\end{array}$} & Canine & $33.4(3.9)$ & 27.5 & 43.2 & $35.2(4.8)$ & 26.1 & 43.5 & $1.9(2.7)$ & -3.5 & 6.4 & 0.0086 \\
\hline & Premolar & $39.4(4.7)$ & 30.1 & 48.1 & $41.5(3.9)$ & 34.6 & 48.0 & $2.1(2.4)$ & -3.3 & 6.4 & 0.0006 \\
\hline & Molar & $56.5(6.1)$ & 42.3 & 67.4 & $57.2(6.3)$ & 42.4 & 67.2 & $0.7(3.5)$ & -5.4 & 9.1 & 0.3833 \\
\hline \multirow{6}{*}{$\begin{array}{c}\text { Buccal alveolar } \\
\text { height }\end{array}$} & Left canine & $7.8(3.6)$ & 1.2 & 16.2 & $7.5(3.3)$ & 1.1 & 12.6 & $-0.3(1.3)$ & -4.1 & 2.9 & 0.0953 \\
\hline & Left premolar & $10.6(2.8)$ & 3.6 & 16.0 & $9.3(3.5)$ & 0.0 & 14.5 & $-1.3(2.9)$ & -11.4 & 2.9 & 0.0202 \\
\hline & Left molar & $11.8(2.0)$ & 8.7 & 16.4 & $10.5(3.2)$ & 0.0 & 15.2 & $-1.2(3.1)$ & -12.5 & 2.0 & 0.0842 \\
\hline & Right canine & $6.8(2.4)$ & 1.1 & 11.9 & $6.6(2.5)$ & 0.3 & 12.7 & $-0.2(1.2)$ & -3.0 & 2.5 & 0.3575 \\
\hline & Right premolar & $10.2(3.4)$ & 2.3 & 15.2 & $8.7(3.9)$ & 0.0 & 14.5 & $-1.5(2.8)$ & -11.9 & 1.4 & 0.0105 \\
\hline & Right molar & $12.1(1.9)$ & 9.6 & 15.7 & $11.0(2.5)$ & 3.8 & 14.1 & $-1.0(2.2)$ & -9.0 & 3.1 & 0.0037 \\
\hline \multirow{12}{*}{$\begin{array}{l}\text { Buccal alveolar } \\
\text { width }\end{array}$} & Left canine (apex) & $3.7(1.4)$ & 2.1 & 8.2 & $2.9(1.0)$ & 1.3 & 5.2 & $-0.9(1.3)$ & -5.1 & 0.9 & 0.0008 \\
\hline & Left canine (middle third) & $1.6(0.5)$ & 0.8 & 2.9 & $1.4(0.4)$ & 0.5 & 2.1 & $-0.2(0.3)$ & -0.8 & 0.4 & 0.0225 \\
\hline & Left premolar (apex) & $1.9(0.9)$ & 0.6 & 3.6 & $1.2(0.8)$ & 0.0 & 3.6 & $-0.6(0.7)$ & -2.2 & 0.8 & 0.0005 \\
\hline & Left premolar (middle third) & $1.6(0.5)$ & 0.9 & 2.7 & $1.2(0.5)$ & 0.0 & 2.2 & $-0.4(0.4)$ & -1.4 & 0.1 & 0.0001 \\
\hline & Left molar (apex) & $3.6(1.8)$ & 0.9 & 8.1 & $2.5(1.9)$ & 0.0 & 8.1 & $-1.0(1.3)$ & -4.0 & 1.5 & 0.0032 \\
\hline & Left molar (middle third) & $1.5(0.5)$ & 0.6 & 2.2 & $0.9(0.5)$ & 0.0 & 1.6 & $-0.6(0.6)$ & -1.8 & 0.1 & 0.0001 \\
\hline & Right canine (apex) & $3.1(1.2)$ & 1.6 & 6.2 & $2.6(0.9)$ & 1.1 & 4.5 & $-0.5(1.1)$ & -2.5 & 2.8 & 0.0191 \\
\hline & Right canine (middle third) & $1.3(0.4)$ & 0.7 & 2.0 & $1.2(0.3)$ & 0.6 & 1.8 & $-0.2(0.3)$ & -0.7 & 0.4 & 0.0065 \\
\hline & Right premolar (apex) & $1.7(0.7)$ & 0.7 & 3.0 & $1.1(0.6)$ & 0.0 & 2.7 & $-0.6(0.7)$ & -1.9 & 0.7 & 0.0005 \\
\hline & Right premolar (middle third) & $1.7(0.5)$ & 0.9 & 2.9 & $1.2(0.7)$ & 0.0 & 2.5 & $-0.5(0.5)$ & -1.7 & 0.6 & 0.0003 \\
\hline & Right molar (apex) & $4.1(2.6)$ & 0.7 & 11.0 & $2.9(1.9)$ & 0.0 & 8.6 & $-1.2(1.1)$ & -4.0 & 0.0 & $<0.0001$ \\
\hline & Right molar (middle third) & $1.7(0.6)$ & 0.9 & 2.9 & $1.2(0.5)$ & 0.0 & 2.0 & $-0.5(0.4)$ & -1.2 & 0.1 & 0.0001 \\
\hline \multirow{6}{*}{$\begin{array}{c}\text { Palatal alveolar } \\
\text { height }\end{array}$} & Left canine & $10.2(3.5)$ & 2.1 & 17.7 & $9.4(3.2)$ & 1.4 & 13.7 & $-0.8(1.7)$ & -5.4 & 2.9 & 0.0353 \\
\hline & Left premolar & $10.6(2.6)$ & 5.0 & 15.8 & $10.3(2.9)$ & 4.8 & 16.1 & $-0.2(1.7)$ & -2.9 & 5.7 & 0.1918 \\
\hline & Left molar & $11.7(1.9)$ & 8.6 & 16.9 & $12.1(2.2)$ & 8.6 & 16.8 & $0.4(1.5)$ & -2.6 & 2.6 & 0.2505 \\
\hline & Right canine & $9.8(2.8)$ & 2.4 & 14.6 & $9.6(2.8)$ & 1.4 & 14.7 & $-0.2(1.2)$ & -1.6 & 3.0 & 0.2123 \\
\hline & Right premolar & $10.7(3.5)$ & 4.2 & 17.4 & $10.3(3.3)$ & 2.7 & 15.2 & $-0.4(1.8)$ & -4.5 & 3.7 & 0.2896 \\
\hline & Right molar & $12.6(2.1)$ & 8.9 & 16.4 & $12.7(2.5)$ & 8.5 & 17.8 & $0.1(1.1)$ & -1.3 & 2.0 & 1.0000 \\
\hline \multirow{6}{*}{$\begin{array}{l}\text { Palatal alveolar } \\
\text { width }\end{array}$} & Left canine & $4.3(2.6)$ & 2.1 & 11.1 & $3.8(2.5)$ & 1.6 & 11.1 & $-0.5(0.9)$ & -3.0 & 0.8 & 0.0388 \\
\hline & Left premolar & $1.7(0.5)$ & 0.6 & 2.5 & $1.8(0.5)$ & 1.2 & 3.0 & $0.1(0.6)$ & -0.8 & 1.7 & 0.9491 \\
\hline & Left molar & $1.5(0.5)$ & 0.9 & 2.5 & $2.0(0.6)$ & 0.8 & 3.5 & $0.4(0.7)$ & -0.7 & 2.4 & 0.0049 \\
\hline & Right canine & $3.5(2.1)$ & 1.3 & 8.2 & $3.3(2.3)$ & 1.5 & 9.2 & $-0.2(0.8)$ & -1.4 & 1.4 & 0.2881 \\
\hline & Right premolar & $1.5(0.5)$ & 0.8 & 2.6 & $1.8(0.7)$ & 1.0 & 4.3 & $0.2(0.5)$ & -0.7 & 1.7 & 0.0486 \\
\hline & Right molar & $1.6(0.9)$ & 0.7 & 4.9 & $2.1(0.8)$ & 1.0 & 4.4 & $0.5(0.8)$ & -0.8 & 2.5 & 0.0091 \\
\hline \multirow{6}{*}{$\begin{array}{l}\text { Buccal-lingual } \\
\text { angulation }\end{array}$} & Left canine & $100.9(4.9)$ & 90.0 & 113.0 & $100.6(4.0)$ & 95.4 & 111.2 & $-0.2(4.1)$ & -6.5 & 11.0 & 0.2341 \\
\hline & Left premolar & $97.4(5.1)$ & 87.7 & 105.6 & $99.3(4.7)$ & 89.2 & 107.9 & $1.8(3.8)$ & -5.0 & 10.3 & 0.0336 \\
\hline & Left molar & $92.6(6.0)$ & 83.9 & 106.2 & $96.5(4.9)$ & 88.0 & 106.2 & $3.9(4.1)$ & -5.1 & 9.9 & 0.0006 \\
\hline & Right canine & $103.6(8.0)$ & 93.2 & 119.8 & $102.1(5.6)$ & 95.3 & 117.4 & $-1.6(4.6)$ & -9.8 & 6.6 & 0.1562 \\
\hline & Right premolar & $97.3(6.1)$ & 86.1 & 105.9 & $100.0(5.0)$ & 88.7 & 107.5 & $2.7(4.8)$ & -7.1 & 10.8 & 0.0220 \\
\hline & Right molar & $92.2(8.8)$ & 82.3 & 113.7 & $95.1(7.3)$ & 85.1 & 110.7 & $2.9(4.6)$ & -5.0 & 11.6 & 0.0121 \\
\hline \multirow{6}{*}{$\begin{array}{l}\text { Alveolar bone } \\
\text { tipping (buccal) }\end{array}$} & Left canine & 103.5 (5.1) & 94.6 & 114.2 & $103.9(5.2)$ & 97.0 & 114.9 & $0.4(5.2)$ & -8.6 & 11.3 & 0.5768 \\
\hline & Left premolar & $105.1(8.5)$ & 85.4 & 121.8 & $108.4(6.1)$ & 94.7 & 117.5 & $3.3(8.9)$ & -20.1 & 25.8 & 0.0224 \\
\hline & Left molar & $89.1(7.0)$ & 79.5 & 103.9 & $96.8(5.6)$ & 85.9 & 106.9 & $7.8(6.3)$ & -5.7 & 25.3 & $<0.0001$ \\
\hline & Right canine & $98.4(31.4)$ & 11.4 & 130.9 & $106.5(7.8)$ & 92.0 & 127.0 & 8.1 (31.2) & -21.6 & 100.9 & 0.9530 \\
\hline & Right premolar & $101.2(22.4)$ & 9.1 & 115.3 & $108.6(6.3)$ & 95.0 & 118.6 & $7.4(24.2)$ & -10.3 & 107.0 & 0.0743 \\
\hline & Right molar & $86.0(9.7)$ & 71.3 & 104.5 & $92.2(11.8)$ & 59.8 & 116.2 & $6.2(10.1)$ & -25.7 & 20.3 & 0.0031 \\
\hline \multirow{6}{*}{$\begin{array}{l}\text { Alveolar bone } \\
\text { tipping (palatal) }\end{array}$} & Left canine & $129.6(10.7)$ & 114.9 & 160.0 & $132.7(10.6)$ & 116.9 & 158.6 & $3.1(9.3)$ & -12.1 & 29.2 & 0.1769 \\
\hline & Left premolar & $118.0(10.5)$ & 99.7 & 141.1 & $117.4(8.8)$ & 95.5 & 131.3 & $-0.6(10.1)$ & -28.5 & 21.9 & 0.9273 \\
\hline & Left molar & $111.0(9.0)$ & 90.7 & 129.2 & $114.7(9.7)$ & 98.3 & 133.3 & $3.7(11.3)$ & -28.9 & 21.8 & 0.0595 \\
\hline & Right canine & $132.6(7.8)$ & 118.3 & 150.9 & $131.6(10.5)$ & 107.7 & 158.5 & $-1.0(10.1)$ & -14.5 & 34.6 & 0.2453 \\
\hline & Right premolar & $115.7(11.9)$ & 99.1 & 135.8 & $118.5(10.0)$ & 105.7 & 138.2 & $2.8(11.8)$ & -22.4 & 21.3 & 0.2196 \\
\hline & Right molar & $105.1(23.5)$ & 20.7 & 133.0 & $109.6(10.0)$ & 97.5 & 139.3 & $4.5(22.0)$ & -22.0 & 80.3 & 0.4980 \\
\hline
\end{tabular}


Table 3 - Descriptive statistics of Group 2 (0.8 mm/day): measures changes from pre- to post-expansion

\begin{tabular}{|c|c|c|c|c|c|c|c|c|c|c|c|}
\hline \multirow{2}{*}{\multicolumn{2}{|c|}{ Group 2 (0.8 mm per day) }} & \multicolumn{3}{|c|}{ Pre-expansion } & \multicolumn{3}{|c|}{ Post-expansion } & \multicolumn{3}{|c|}{ Change } & \multirow{2}{*}{ (p-Value) } \\
\hline & & Mean (SD) & Min & $\operatorname{Max}$ & Mean (SD) & Min & Max & Mean (SD) & Min & $\operatorname{Max}$ & \\
\hline \multirow{3}{*}{$\begin{array}{l}\text { Intra-arch } \\
\text { width }\end{array}$} & Canine & $31.7(0.9)$ & 24.8 & 40.0 & $35.5(1.6)$ & 24.7 & 57.4 & $3.8(1.4)$ & -2.3 & 27.7 & 0.0001 \\
\hline & Premolar & $37.8(0.5)$ & 33.1 & 41.8 & $44.1(0.7)$ & 37.1 & 50.3 & $6.3(0.6)$ & 0.2 & 10.5 & $<0.0001$ \\
\hline & Molar & $46.8(0.7)$ & 41.3 & 52.3 & $51.8(1.2)$ & 34.7 & 59.9 & $5.0(1.1)$ & -12.9 & 8.9 & 0.0011 \\
\hline \multirow{3}{*}{$\begin{array}{l}\text { Maxillary base } \\
\text { width }\end{array}$} & Canine & $33.7(1.1)$ & 25.6 & 41.0 & $35.5(1.1)$ & 26.0 & 43.7 & $1.8(0.5)$ & -1.6 & 5.0 & 0.0010 \\
\hline & Premolar & $37.7(1.2)$ & 28.8 & 48.0 & $41.0(1.6)$ & 27.8 & 56.6 & $3.3(1.1)$ & -1.6 & 19.0 & 0.0010 \\
\hline & Molar & $53.2(1.5)$ & 33.8 & 66.7 & $54.7(1.5)$ & 36.5 & 67.0 & $1.5(0.7)$ & -5.5 & 6.7 & 0.0332 \\
\hline \multirow{6}{*}{$\begin{array}{c}\text { Buccal } \\
\text { alveolar height }\end{array}$} & Left canine & $15.4(1.4)$ & 2.3 & 24.1 & $14.4(1.4)$ & 2.0 & 22.8 & $-1.0(0.3)$ & -4.6 & 1.0 & 0.0116 \\
\hline & Left premolar & $15.9(1.1)$ & 5.1 & 21.8 & $14.0(1.2)$ & 4.7 & 21.2 & $-1.9(0.6)$ & -11.2 & 0.3 & 0.0001 \\
\hline & Left molar & $13.6(0.6)$ & 9.7 & 19.9 & $12.1(0.7)$ & 7.0 & 17.9 & $-1.6(0.3)$ & -3.6 & 1.0 & 0.0001 \\
\hline & Right canine & $15.0(1.1)$ & 5.8 & 23.9 & $13.6(1.1)$ & 3.5 & 22.9 & $-1.3(0.4)$ & -4.7 & 1.1 & 0.0029 \\
\hline & Right premolar & $15.6(1.1)$ & 5.1 & 24.6 & $12.8(1.3)$ & 5.2 & 23.8 & $-2.8(1.0)$ & -14.0 & 1.1 & 0.0009 \\
\hline & Right Molar & $13.5(0.8)$ & 6.4 & 21.5 & $11.4(1.1)$ & 2.7 & 21.5 & $-2.2(0.6)$ & -9.8 & 0.2 & $<0.0001$ \\
\hline \multirow{12}{*}{$\begin{array}{c}\text { Buccal } \\
\text { alveolar width }\end{array}$} & Left canine (apex) & $4.5(0.3)$ & 2.2 & 7.2 & $4.2(0.4)$ & 0.2 & 8.2 & $-0.3(0.2)$ & -3.7 & 1.0 & 0.4406 \\
\hline & Left canine (middle third) & $1.9(0.2)$ & 0.7 & 3.8 & $1.5(0.2)$ & 0.2 & 3.4 & $-0.4(0.2)$ & -2.1 & 0.5 & 0.1381 \\
\hline & Left premolar (apex) & $1.8(0.2)$ & 0.5 & 3.7 & $1.4(0.2)$ & 0.3 & 3.2 & $-0.4(0.2)$ & -1.9 & 1.0 & 0.0558 \\
\hline & Left premolar (middle third) & $1.3(0.2)$ & 0.4 & 3.6 & $1.1(0.1)$ & 0.2 & 3.2 & $-0.2(0.1)$ & -0.9 & 0.3 & 0.0107 \\
\hline & Left molar (apex) & $3.4(0.5)$ & 0.6 & 8.8 & $2.9(0.4)$ & 0.2 & 7.7 & $-0.5(0.3)$ & -4.0 & 1.8 & 0.1326 \\
\hline & Left molar (middle third) & $1.4(0.2)$ & 0.3 & 3.0 & $1.0(0.1)$ & 0.2 & 2.2 & $-0.3(0.1)$ & -1.2 & 0.8 & 0.0058 \\
\hline & Right canine (apex) & $4.1(0.3)$ & 1.8 & 6.7 & $3.5(0.3)$ & 1.1 & 6.2 & $-0.6(0.2)$ & -3.4 & 1.1 & 0.0071 \\
\hline & Right canine (middle third) & $1.7(0.2)$ & 0.5 & 4.2 & $1.5(0.2)$ & 0.2 & 3.2 & $-0.2(0.1)$ & -1.0 & 0.3 & 0.0063 \\
\hline & Right premolar (apex) & $1.5(0.1)$ & 0.5 & 2.5 & $1.2(0.2)$ & 0.0 & 2.4 & $-0.3(0.1)$ & -1.5 & 0.6 & 0.0693 \\
\hline & Right premolar (middle third) & $1.3(0.1)$ & 0.5 & 2.2 & $0.9(0.1)$ & 0.0 & 1.9 & $-0.4(0.1)$ & -1.5 & 0.4 & 0.0008 \\
\hline & Right molar (apex) & $3.4(0.5)$ & 0.4 & 10.4 & $2.8(0.5)$ & 0.0 & 8.3 & $-0.6(0.3)$ & -2.9 & 2.1 & 0.0177 \\
\hline & Right Molar (middle third) & $1.7(0.2)$ & 0.3 & 2.7 & $1.2(0.2)$ & 0.3 & 2.5 & $-0.5(0.1)$ & -1.8 & 0.4 & 0.0005 \\
\hline \multirow{6}{*}{$\begin{array}{c}\text { Palatal alveolar } \\
\text { height }\end{array}$} & Left canine & $18.4(1.2)$ & 9.7 & 27.7 & $17.4(1.3)$ & 9.1 & 27.0 & $-1.0(0.5)$ & -6.6 & 3.4 & 0.0397 \\
\hline & Left premolar & $15.8(1.1)$ & 4.8 & 21.8 & $15.7(1.1)$ & 4.8 & 22.0 & $-0.1(0.4)$ & -2.7 & 4.6 & 0.5150 \\
\hline & Left molar & $13.8(0.6)$ & 6.4 & 19.9 & $13.4(0.6)$ & 6.3 & 18.3 & $-0.4(0.3)$ & -2.9 & 2.2 & 0.1001 \\
\hline & Right canine & $17.9(1.4)$ & 9.0 & 28.7 & 17.3 (1.3) & 7.4 & 26.8 & $-0.6(0.3)$ & -3.5 & 0.7 & 0.0616 \\
\hline & Right premolar & $16.6(1.1)$ & 7.9 & 25.4 & $16.5(1.1)$ & 7.2 & 25.5 & $-0.1(0.2)$ & -2.2 & 2.0 & 0.6048 \\
\hline & Right molar & $14.7(0.6)$ & 9.5 & 21.2 & $13.8(0.7)$ & 7.1 & 18.9 & $-0.9(0.4)$ & -6.4 & 1.3 & 0.0085 \\
\hline \multirow{6}{*}{$\begin{array}{c}\text { Palatal alveolar } \\
\text { width }\end{array}$} & Left canine & $3.7(0.3)$ & 2.2 & 6.4 & $3.2(0.2)$ & 1.8 & 5.0 & $-0.5(0.2)$ & -2.4 & 0.6 & 0.0430 \\
\hline & Left premolar & $1.8(0.5)$ & 0.5 & 8.1 & $1.8(0.5)$ & 0.5 & 8.9 & $0.0(0.3)$ & -3.6 & 1.1 & 0.5078 \\
\hline & Left molar & $1.0(0.1)$ & 0.5 & 1.5 & $1.3(0.1)$ & 0.6 & 2.6 & $0.3(0.1)$ & -0.5 & 1.2 & 0.0224 \\
\hline & Right canine & $3.4(0.2)$ & 1.7 & 4.7 & $3.2(0.2)$ & 2.1 & 4.2 & $-0.2(0.1)$ & -0.9 & 0.6 & 0.1143 \\
\hline & Right premolar & $2.6(0.7)$ & 0.5 & 12.4 & $2.6(0.6)$ & 0.6 & 11.2 & $0.0(0.3)$ & -2.5 & 2.3 & 0.7725 \\
\hline & Right molar & $1.1(0.1)$ & 0.6 & 2.1 & $1.2(0.1)$ & 0.5 & 2.0 & $0.2(0.1)$ & -1.0 & 0.9 & 0.1290 \\
\hline \multirow{6}{*}{$\begin{array}{l}\text { Buccal-lingual } \\
\text { angulation }\end{array}$} & Left canine & $109.5(5.3)$ & 57.2 & 136.1 & $105.3(4.4)$ & 50.5 & 125.3 & $-4.2(2.3)$ & -19.1 & 20.0 & 0.0505 \\
\hline & Left premolar & $105.0(5.3)$ & 61.2 & 145.4 & $111.0(3.7)$ & 77.5 & 137.8 & $5.9(3.0)$ & -21.1 & 26.4 & 0.0898 \\
\hline & Left molar & $98.3(3.0)$ & 76.5 & 126.6 & $111.2(3.2)$ & 92.0 & 146.2 & $13.0(2.2)$ & -3.4 & 32.9 & $<0.0001$ \\
\hline & Right canine & $104.6(4.4)$ & 54.0 & 129.0 & $108.2(4.6)$ & 60.3 & 137.8 & $3.6(3.0)$ & -11.3 & 45.6 & 0.3927 \\
\hline & Right premolar & $97.3(2.8)$ & 71.3 & 114.9 & $109.1(4.1)$ & 79.5 & 136.3 & $11.8(3.4)$ & -10.9 & 40.6 & 0.0034 \\
\hline & Right molar & $92.7(2.3)$ & 65.9 & 110.3 & $106.6(2.6)$ & 91.5 & 126.7 & $13.9(2.5)$ & -2.1 & 39.6 & $<0.0001$ \\
\hline \multirow{6}{*}{$\begin{array}{c}\text { Alveolar } \\
\text { bone tipping } \\
\text { (buccal) }\end{array}$} & Left canine & $113.4(5.0)$ & 64.9 & 138.5 & $110.4(3.7)$ & 73.2 & 133.6 & $-3.0(3.4)$ & -26.3 & 37.4 & 0.1964 \\
\hline & Left premolar & $120.7(4.8)$ & 85.0 & 154.3 & $124.2(3.4)$ & 88.8 & 144.6 & $3.5(3.3)$ & -19.0 & 39.0 & 0.3038 \\
\hline & Left molar & $100.1(4.0)$ & 73.1 & 132.0 & $111.1(4.3)$ & 71.5 & 149.8 & $10.9(2.7)$ & -9.5 & 29.5 & 0.0014 \\
\hline & Right canine & $113.0(3.3)$ & 85.7 & 138.9 & $118.9(3.8)$ & 88.6 & 152.2 & $6.0(3.4)$ & -13.5 & 45.9 & 0.1269 \\
\hline & Right premolar & $118.2(3.2)$ & 98.7 & 151.6 & $125.9(2.7)$ & 98.3 & 153.1 & $7.7(4.2)$ & -29.3 & 46.3 & 0.0719 \\
\hline & Right molar & $98.2(4.0)$ & 60.2 & 128.5 & $108.7(4.0)$ & 73.8 & 138.1 & 10.5 (3.1) & -13.8 & 45.0 & 0.0024 \\
\hline \multirow{6}{*}{$\begin{array}{c}\text { Alveolar } \\
\text { bone tipping } \\
\text { (palatal) }\end{array}$} & Left canine & $150.7(3.5)$ & 112.2 & 169.0 & $150.0(2.4)$ & 135.7 & 165.2 & $-0.7(3.2)$ & -24.4 & 33.5 & 0.7536 \\
\hline & Left premolar & $139.6(4.7)$ & 106.6 & 167.0 & $141.1(3.3)$ & 113.6 & 159.5 & $1.6(3.4)$ & -25.2 & 29.4 & 0.9751 \\
\hline & Left molar & $123.6(2.8)$ & 93.6 & 146.0 & $124.8(2.5)$ & 98.7 & 149.0 & $1.2(2.9)$ & -28.8 & 16.6 & 0.4900 \\
\hline & Right canine & $150.2(3.4)$ & 113.7 & 163.9 & $149.9(3.1)$ & 124.1 & 168.8 & $-0.3(2.4)$ & -19.8 & 14.4 & 0.9299 \\
\hline & Right premolar & $134.5(4.5)$ & 99.4 & 170.1 & $133.4(3.9)$ & 98.9 & 158.8 & $-1.2(4.7)$ & -53.2 & 34.9 & 0.7019 \\
\hline & Right molar & $115.0(3.0)$ & 99.2 & 141.4 & $119.8(3.2)$ & 101.5 & 149.6 & $4.9(3.0)$ & -35.7 & 27.1 & 0.0230 \\
\hline
\end{tabular}




\section{DISCUSSION}

Maxillary expansion has been advocated as the preferred method for the correction of maxillary arch constriction and for correcting disharmonies between the maxillary and mandibular arches. ${ }^{13,23,24}$ There is lack of literature describing the changes in buccal bone and potential root resorption due to different rates of activation of RPE that are commonly used in the practice of orthodontics. Faster activation rate is expected to cause more decrease in alveolar bone width and greater incidence of adverse effects than a slower activation rate, possibly because the bone cannot adapt to the heavier forces generated by faster activation rates of RPE. The present study investigated the changes in alveolar bone height and thickness as well as the adverse effects such as amount of alveolar tipping, dental tipping, fenestration and dehiscence of anchorage teeth associated with using two different RPE activation protocols.

Conventional radiographs, such as cephalometric and panoramic radiographs, are not appropriate for examining buccal bone or periodontal changes after RPE. ${ }^{25}$ Such radiographs are merely two-dimensional representations of three-dimensional structures and do not allow the orthodontist to evaluate and measure changes in buccal bone. ${ }^{25}$ These radiographs have other limitations regarding the superimposition of anatomic structures and difficulty in reproducing angles over time. ${ }^{26}$ Moreover, the resorption of the buccal plate cannot be distinguished from lingual defects. ${ }^{27}$ With the development of CBCT, it is now possible to objectively measure skeletal and dental changes in all three dimensions and without superimposition of the neighboring structures. ${ }^{3,25,28}$ Recent advancements in CBCT technology have also allowed the method to be more affordable for the dental office and to be safer for the patient due to decreased exposure to ionizing radiation.

The results of this study demonstrated that an activation rate of $0.5 \mathrm{~mm} /$ day is effective in increasing intra-arch widths. The activation rate of $0.5 \mathrm{~mm} /$ day resulted in an increase in intra-arch widths that are approximately three times greater than the increase in maxillary base width, consistent with the findings from other reports. ${ }^{7,13,14}$ The activation rate of $0.8 \mathrm{~mm} /$ day was more effective in increasing intra-arch widths compared to activating $0.5 \mathrm{~mm} /$ day, and the increase in intra-arch widths was still approximately three times greater than the increase in maxillary base width. Both activation rates resulted in buccal tipping of the maxillary molars. The greatest amount of tipping occurred in the maxillary first molars. The amount of tipping increased from the anterior region to the molar region, and this was more prominent when activating $0.8 \mathrm{~mm} /$ day. This increased tipping associated with $0.8 \mathrm{~mm} /$ day activation rate may predispose to significant loss of buccal alveolar bone.

There were also incidences of dehiscence observed in the post-expansion 3D images. Both groups had two patients with incidence of dehiscence. Baysal et $\mathrm{al}^{3}$ reported incidence of dehiscence in their study between $2.5 \%$ and $55 \%$, which is consistent with the findings from the present study. It may be possible to suggest that the minimal amount of buccal alveolar bone supporting the teeth may predispose the patient to dehiscence. Clinicians should, thus, carefully assess the amount of alveolar bone supporting the teeth prior to including expansion in the treatment plan for a patient.

Although the treatment outcomes of palatal expansion have been reported for many years, the question of which expansion protocol should be used in each case is still controversial. Several studies compared slow and rapid maxillary expansion using QuadHelix and Hyrax appliances, respectively. They indicated that slow maxillary expansion has been related to greater buccal tipping of molars, more physiologic effects on sutural tissues, lower orthopedic effects and better bone formation in the intermaxillary sutures, which minimizes the amount of relapse as compared to rapid maxillary expansion. ${ }^{29-32}$ The findings of the present study showed that the amount of buccal crown tipping of molars and buccal tipping of the alveolar bone was greater when activating $0.8 \mathrm{~mm} /$ day compared to activating $0.5 \mathrm{~mm} /$ day. These contradictory results could be explained by the difference in force delivery system, since Quad-Helix appliance delivers lighter continuous force while Hyrax appliance delivers heavy interrupted force. This indicates that the force delivery system should carefully be considered when treatment of posterior crossbites is advocated.

In conclusion, the results of this study indicated that both activation rates are effective in increasing intraarch widths, although $0.8 \mathrm{~mm} /$ day was more effective. 
Both activation rates caused significant decreases in the height and width of buccal alveolar bone, and significant increases in buccal tipping of maxillary first molars. Both activation rates are also associated with the risk of some adverse effects such as alveolar tipping, dental tipping and dehiscence, although the more rapid activation rates result in more dental tipping. Limitations of the current study that might limit the generability of the findings include the cross-sectional retrospective design and the sample size.
1. Bell RA. A review of maxillary expansion in relation to rate of expansion and patient's age. Am J Orthod. 1982 Jan;81(1):32-7.

2. Pangrazio-Kulbersh V, Jezdimir B, de Deus Haughey M, Kulbersh R, Wine P. Kaczynski R. CBCT assessment of alveolar buccal bone level after RME. Angle Orthod. 2013 Jan;83(1):110-6

3. Baysal A, Uysal T, Veli I, Ozer T, Karadede I, Hekimoglu S. Evaluation of alveolar bone loss following rapid maxillary expansion using cone-beam computed tomography. Korean J Orthod. 2013 Apr;43(2):83-95.

4. Zimring JF, Isaacson RJ. Forces produced by rapid maxillary expansion. Forces present during retention. Angle Orthod. 1965 July:35:178-86.

5. Starnbach H, Bayne D, Cleall J, Subtelny JD. Facioskeletal and dental changes resulting from rapid maxillary expansion. Angle Orthod. 1966 Apr;36(2):152-64

6. Woller JL, Kim KB, Behrents RG, Buschang PH. An assessment of the maxilla after rapid maxillary expansion using cone beam computed tomography in growing children. Dental Press J Orthod. 2014 Jan-Feb;19(1):26-35.

7. Wertz R, Dreskin M. Midpalatal suture opening: a normative study. Am J Orthod. 1977 Apr; 71(4):367-81.

8. Smith T, Ghoneima A, Stewart K, Liu S, Eckert G, Halum S, et al. Threedimensional computed tomography analysis of airway volume changes after rapid maxillary expansion. Am J Orthod Dentofacial Orthop. 2012 May:141(5):618-26.

9. Timms DJ. A study of basal movement with rapid maxillary expansion. Am J Orthod. 1980 May:77(5):500-7.

10. Christie KF, Boucher N, Chung CH. Effects of bonded rapid palatal expansion on the transverse dimensions of the maxilla: a cone-beam computed tomography study. Am J Orthod Dentofacial Orthop. 2010 Apr:137(4 Suppl):S79-85.

11. Baydas B, Yavuz I, Uslu H, Dagsuyu IM, Ceylan I. Nonsurgical rapid maxillary expansion effects on craniofacial structures in young adult females. A bone scintigraphy study. A bone scintigraphy study. Angle Orthod. 2006 Sept:76(5):759-67.

12. Bishara SE, Staley RN. Maxillary expansion: clinical implications. Am J Orthod Dentofacial Orthop. 1987 Jan;91(1):3-14.

13. Ghoneima A, Abdel-Fattah E, Eraso F, Fardo D, Kula K, Hartsfield J. Skeletal and dental changes after rapid maxillary expansion: a computed tomography study Aust Orthod J. 2010 Nov:26(2):141-8.

14. Krebs A. Midpalatal suture expansion studies by the implant method over sevenyear period. Rep Congr Eur Orthod Soc. 1964:40:131-42.

15. Baysal A, Karadede I, Hekimoglu S, Ucar F, Ozer T, Veli I, et al. Evaluation of root resorption following rapid maxillary expansion using cone-beam computed tomography. Angle Orthod. 2012 May; 82(3):488-94.

16. Brunetto M, Andriani JS, Ribeiro GL, Locks A, Correa M, Correa LR. Threedimensional assessment of buccal alveolar bone after rapid and slow maxillary expansion: a clinical trial study. Am J Orthod Dentofacial Orthop. 2013 May;143(5):633-44.
17. Hicks EP. Slow maxillary expansion. A clinical study of the skeletal versus dental response to low-magnitude force. Am J Orthod. 1978 Feb;73(2):121-41.

18. Barber AF, Sims MR. Rapid maxillary expansion and external root resorption in man: a scanning electron microscope study. Am J Orthod. 1981 Jun;79(6):63052.

19. Rungcharassaeng K, Caruso JM, Kan JY, Kim J, Taylor G. Factors affecting buccal bone changes of maxillary posterior teeth after rapid maxillary expansion. Am J Orthod Dentofacial Orthop. 2007 Oct:132(4):428.e1-8.

20. Langford SR, Sims MR. Root surface resorption, repair, and periodontal attachment following rapid maxillary expansion in man. Am J Orthod. 1982 Feb; 81(2):108-15.

21. Odenrick L, Karlander EL, Pierce A, Kretschmar U. Surface resorption following two forms of rapid maxillary expansion. Eur J Orthod. 1991 Aug;13(4):264-70.

22. Erverdi N, Okar I, Kucukkeles N, Arbak S. A comparison of two different rapid palatal expansion techniques from the point of root resorption. Am J Orthod Dentofacial Orthop. 1994 July:106(1):47-51.

23. Handelman CS, Wang L, BeGole EA, Haas AJ. Nonsurgical rapid maxillary expansion in adults: report on 47 cases using the Haas expander. Angle Orthod. 2000 Apr:70(2):129-44.

24. McNamara JA. Maxillary transverse deficiency. Am J Orthod Dentofacial Orthop. 2000 May:117(5):567-70.

25. Akyalcin S, Schaefer JS, English JD, Stephens CR, Winkelmann S. A cone-beam computed tomography evaluation of buccal bone thickness following maxillary expansion. Imaging Sci Dent. 2013 June; 43(2):85-90.

26. Misch KA, Yi ES, Sarment DP. Accuracy of cone beam computed tomography for periodontal defect measurements. J Periodontol. 2006 July; 77(7):1261-6.

27. Rees TD, Biggs NL, Collings CK. Radiographic interpretation of periodontal osseous lesions. Oral Surg Oral Med Oral Pathol. 1971 July; 32(1):141-53.

28. Walker $L$, Enciso R, Mah J. Three-dimensional localization of maxillary canines with cone-beam computed tomography. Am J Orthod Dentofacial Orthop. 2005 Oct:128(4):418-23.

29. Bell RA. A review of maxillary expansion in relation to rate of expansion and patient's age. Am J Orthod. 1982 Jan; 81(1):32-37.

30. Mew J. Relapse following maxillary expansion. Am J Orthod. 1983 Jan;83(1):5661.

31. Rungcharassaeng K, Caruso JM, Kan JYK, Kim J, Taylor G. Factors affecting buccal bone changes of maxillary posterior teeth after rapid maxillary expansion. Am J Orthod Dentofacial Orthop. 2007 Oct;132: 428.e1-8.

32. Brunetto M, Andriani J, Ribeiro G, Locks A, Correa M, Correa LR. Threedimensional assessment of buccal alveolar bone after rapid and slow maxillary expansion: a clinical trial study. Am J Orthod Dentofacial Orthop. 2013 May;143(5):633-44 